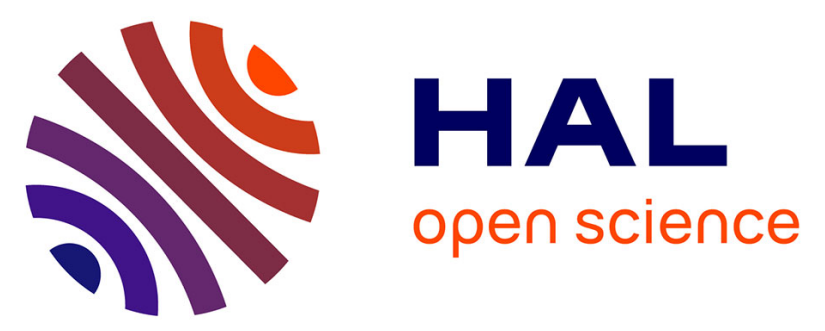

\title{
Relationships between anthropometry, cardiorespiratory fitness indices and physical activity levels in different age and sex groups in rural Senegal (West Africa).
}

Eric Bénéfice, Gnagna Mbaye Ndiaye

\section{- To cite this version:}

Eric Bénéfice, Gnagna Mbaye Ndiaye. Relationships between anthropometry, cardiorespiratory fitness indices and physical activity levels in different age and sex groups in rural Senegal (West Africa).. Annals of Human Biology, 2005, 32 (3), pp.366-82. 10.1080/03014460500097336 . ird-00192621

\section{HAL Id: ird-00192621 \\ https://hal.ird.fr/ird-00192621}

Submitted on 4 Dec 2007

HAL is a multi-disciplinary open access archive for the deposit and dissemination of scientific research documents, whether they are published or not. The documents may come from teaching and research institutions in France or abroad, or from public or private research centers.
L'archive ouverte pluridisciplinaire HAL, est destinée au dépôt et à la diffusion de documents scientifiques de niveau recherche, publiés ou non, émanant des établissements d'enseignement et de recherche français ou étrangers, des laboratoires publics ou privés. 


\title{
Relationships between anthropometry, cardiorespiratory fitness indices and physical activity levels in different age and sex groups in rural Senegal (West Africa)
}

\author{
Eric Bénéfice ${ }^{1}$, Gnagna Ndiaye ${ }^{2}$
}

${ }^{1}$ Epidemiology and Prevention Research Unit (R024), Institut Français de Recherche pour le Développement (IRD, France)

${ }^{2}$ Nutrition Department, Cheikh Anta Diop University (Senegal) and IRD

Address for correspondence

Dr E Benefice

Représentation IRD de La Paz

Calle H Siles \#5297 * Esquina 7 de obrajes

CP 9214

La Paz (Bolivia)

fax: (591 2) 2782944

tel: (591 2) 2782969

mail: benefice@ird.fr 


\section{Summary}

Background: A high level of activity is commonplace in traditional subsistence societies. Physiological characteristics of individuals, including body composition and physical fitness, could be limiting factors when performing daily tasks.

Objectives: To investigate the relationships between cardiorespiratory fitness, nutritional status and physical activity patterns, so as to test the hypothesis that these relationships are less straightforward in children than in adults.

Study design: Four different groups of individuals from rural Senegal were investigated: 99 10-13 years-old children of both sexes (11.1 \pm 1.5 years old) from 2 settings in Senegal (Lambaye and Podor); 43 adolescent girls (15.5 \pm 0.5 years) and 30 adult women (17-40 years).

Methods: Subjects undertook a step-test, and anthropometric measurements were collected. Continuous heart rate (HR) monitoring was performed for 8 to $12 \mathrm{~h}$. The flex-HR method was used to estimate levels of activity (percent of time spent under or over the Flex-HR).

Results: 10-13 years-old children and adolescent girls presented slight degrees of malnutrition. Adult women were apparently not nutritionally deprived. Differences in cardiorespiratory fitness were found among 10-13 years-old children, while adult women performed better than adolescent girls. Children from Lambaye had a higher level of activity than children from Podor. Similarly, adult women were more active than adolescent girls. No relationships were found between cardiorespiratory or anthropometric measurements and percent of time spent above the flex-HR ( $>$ flex-HR) in 10-13 years-old children. In contrast, in adult women and adolescent girls, body composition and cardiorespiratory indices were significant predictors of activity levels.

Conclusion: Our data support the hypothesis that activity levels are less dependent upon physiological characteristics in children than in adults in traditional subsistence societies.

Key-words: Malnutrition, Developing countries, Heart rate recording, Adolescence 


\section{Introduction}

Physical activity is composed of various components (the type of movement, purpose of the activities, behavior, etc.) and can be expressed in several ways (energy cost of activities, analysis of movement, work productivity, etc. ) (Montoye et al. 1996). The terms "energy expenditure" and "physical activity" are not synonymous: physical activity results in energy expenditure in the same way that the basal metabolic rate or the thermic effect of foods (Kohl et al. 2000). The context of daily tasks as well as the physical and social environment are important characteristics of activity. This is especially true for societies living at subsistence levels, where a high level of energy is exerted performing daily household tasks (Bleiberg et al. 1981) and where individual physiological characteristics may be limiting factors in terms of work (Spurr et al. 1975). Hence, malnutrition resulting in weight loss and growth retardation is likely to decrease activity levels. It has been said that a decrease in activity is the "first line of defense" on the part of malnourished children for restoring their energy balance (Spurr 1990). Studies on the daily activity patterns of traditional societies are scarce, though there is currently renewed interest in this subject because of the association between activity and the worldwide epidemic of overweight and obesity that is now affecting developing countries (Jain 2004). However, it must be emphasized that childhood malnutrition remains prevalent in Africa (De Onis et al. 2000).

In traditional subsistence populations, the work load must be shared among family members, and there a strict division of tasks is present according to age and sex. Children and adolescents, especially girls, are frequently involved in daily agricultural or domestic tasks (Benefice et al. 2001). Men are generally in charge of high-energy-demanding muscular tasks (Brun et al. 1981), while women and children are allotted time-consuming tasks (Giampietro and Pimentel 1992) that actually constitute the major part of daily chores. This labor division shapes the physical activity profile of the population in terms of activity levels as well as the nature of the tasks undertaken, and should be considered in any analysis.

A strong link between health and nutritional status, activity levels and work performance probably exists in adults from developing countries (Spurr et al. 1977). The relationship is not clear-cut, and underlying mechanisms have not been accurately elucidated (Spurr et al. 
1977, Thomas and Frankenberg 2002). In children, this association appears to be even less well defined than in adults. Several studies have reported a slight difference in activity levels between chronically malnourished and normal children (Gardner et al. 1990, Torun and Viteri 1993), but it does not appear to be predictive of lower psychomotor development. Less active malnourished children are able to catch up in growth and development when they receive an adequate nutritional supplementation and/or psychosocial stimulation (Meeks-Gardner et al. 1995). It was reported that 10-12-year-old malnourished boys increased their energy expenditure shortly after lunch, but were unable to sustain their efforts for a long period (Spurr and Reina 1988). However, it is possible that marginally malnourished children are able to push back their physiological limits to a certain extent (Torun and Viteri 1993).

In Senegal, in a study on school-age slightly malnourished children 10 to 12 years of age, no association was observed between activity indices and nutritional status, while there were small but significant correlations between activity, physical fitness and motor performance characteristics (Benefice 1998). In contrast, in older adolescent girls, there was a significant positive relationship between body mass index and physical activity (Benefice et al. 2001). Activity patterns also varied according to the location and work situation. In a study comparing the activity of rural adolescents to those transiently migrating to the city, we found that migrants (urban) were more active than non-migrants (rural). There were also differences according to age and maturation: younger, less mature girls were more active than older, more mature adolescents (Garnier and Benefice 2001). It is thus possible that regulation of energy balance through a decrease in physical activity is more flexible in children than in adults

Assessment of physical activity is an important issue. In children, the strength of the correlation between activity and body weight is highly dependent on the method used (Rowlands et al. 2000). Heart rate recording is a traditional objective method for measurement in population studies (Montoye et al. 1996). Initially, heartbeat values were averaged and compared for a set period of time (Bradfield 1971). Later, levels of activities were determined after fixed cut-off values (Gilliam et al. 1981,Saris 1986). Spurr introduced the concept of flex-HR to estimate total energy expenditure in daily tasks (Spurr et al. 1988). The flex-HR is the point where HR breaks-down from rest value during an exercise. This point of differentiation is sometimes defined as the average of the highest HR during rest and the lowest HR during exercise (Leonard 2003). One advantage of the flex-HR method is that 
activity levels reflect the individual subject's fitness rather than being a fixed value defined for a particular population. In the present paper, we used a simplification of the method for human biology studies illustrated in other papers (Panter-Brick et al. 1996a, Yamauchi et al. 2000).

The objective of the present paper was to investigate the relationship between individual physiological competences, physical fitness and nutritional status in terms of daily physical activity levels. Specifically, the working hypothesis was that physical activity patterns are less dependent on physiological characteristics in children than in adolescents or adults. This was based on a series of surveys carried out in school-aged children, adolescents and adult women in northern and central Senegal. 


\section{Methods}

\section{$2.1 \quad$ Study area}

Studies were performed in three regions of Senegal (West Africa): two of these (Lambaye and Niakhar) are in the centre of Senegal in the so-called "peanut basin" and one (Podor) is at the northernmost point of the Senegal River bend. These 3 regions are characterized by a Sahelian climate with a short rainy season mainly from July to October and a long dry season from November to June. Inhabitants are Moslem farmers belonging to different, though related ethnic groups: Tokolor in the north of Senegal (Senegal River valley), Wolof in Lambaye and Sereer in Niakhar (central Senegal). Although cultural differences exist, all these groups share a common Sahelian culture characterized by similar agricultural practices and food consumption habits. Inhabitants subsist on farming and herding. They grow millet (Pennisetum spp and Sorghum vulgare) in association with beans (Vigna unguiculata). In Lambaye and Niakhar they grow peanuts (Arachis hypoogea) for cash. In the Senegal River Valley, modern irrigation permits rice cultivation. The basic diet consists of a bowl of rice with fresh or dried fish at noon and millet couscous with peanut sauce in the evening. The prevalence of malnutrition in Senegal is high: According to the World Health Organization (WHO) global database on growth and malnutrition, more than $25 \%$ of preschool children are stunted (height-for-age $<-2$ z-scores) and $7 \%$ are wasted (weight-for-height $<-2$ z-scores).

\subsection{Sampling}

\subsubsection{0-13 years-old group}

In Lambaye and Podor, children were recruited after a preliminary home-to-home census. Only subjects in good health with the absence of clinically detectable abnormalities in the orthopedic, neuromotor and nutritional spheres were selected. When no birth certificate existed, age was determined with reference to Moslem religious events and by comparison with another child of known age living in the same compound. Children were between 10 and 13 years of age, with the same proportion of boys and girls. Their mean age was $11.1 \pm 1.5$ years. Forty children were from Lambaye (20 girls and 20 boys) and 59 from Podor ( 26 boys 
and 33 girls). There were no age or sex distribution differences between ethnic groups. These children did not present any signs of puberty (breast development, voice change or public hairiness, menarche) at the time of examination. They could be considered as pre-pubescent adolescents. Some results of this study have been previously published (Benefice 1992).

\subsubsection{Adolescent girl group}

Adolescents were drawn from a larger sample of 406 girls followed up yearly within the framework of a longitudinal growth and maturation survey in the Niakhar region (Benefice et al. 2001). Forty-three girls were selected using the same criteria as with children; they undertook all tests and heart rate monitoring. They were $15.5 \pm 0.5$ years old at the time of the survey. Puberty development has been checked on the basis of breast development stage and occurrence of menarche. All girls entered in puberty (breast stage 2). 34 (81\%) were breast stage 3 or above and 8 (19\%) were breast stage 2 (beginning of puberty). Only 10 girls (24\%) already experienced menstruations. This group could be viewed as a mean pubescent group, thus differing from the former group.

\subsubsection{Adult women's group}

Thirty women were chosen from the Podor area. They belonged to a group of women followed up for 2 years within the framework of a survey on seasonal changes in the activity pattern. From a database of 260 women, 60 were selected according to the following criteria: age between 17 and 40 years; permanent residence in the study area; married with children under 5 years of age; not pregnant and in good heath at the time of inclusion (Benefice et al. 1996). In the present paper, we present findings for only 30 women who could be traced one year after the initial survey and who completed all tests.

All subjects participated voluntarily in the study. Children, parents and traditional village chiefs were given complete information concerning the goals of the survey. As the individuals were often illiterate, oral consent was requested. The study protocol was reviewed and approved during joint yearly conventions of the Senegal Ministry of Research and the French Institute of Research for Development (IRD). 


\subsection{Anthropometry}

Anthropometric measurements were taken according to recommended techniques (Lohman et al. 1988). All subjects were weighed barefoot and lightly clothed using an electronic scale accurate to $100 \mathrm{~g}$. Height (in $\mathrm{cm}$ ) was measured standing upright with eyes on a horizontal plane, using a portable Harpenden anthropometer. Mid-arm circumference (cm) was measured on the left side at mid-distance between the acromion and the olecraneon after marking the site on the skin. Then, triceps and biceps skinfolds were measured at the same site with a Holtain caliper. Subscapular and suprailiac skinfolds were also taken. In adult women, only the triceps skinfold was measured. Each measurement was carried out in duplicate and the average value was recorded to minimize variance. The body mass index (BMI, $\mathrm{kg} / \mathrm{m} 2$ ) was calculated as weight/ (height) 2. Arm muscle circumference (AMC, $\mathrm{cm}=$ arm circumference $-\pi^{*}$ triceps skinfold) was used as a proxy for muscle mass (Gurney and Jelliffe 1973). Nutritional indices of weight-for-age (W-age) or Height-for-age (H-age) were calculated according to the current WHO recommendations to characterize underweight and chronic malnutrition (Who 1995).

\subsection{Cardiorespiratory fitness}

Cardiorespiratory fitness was estimated after a submaximal step test using the following protocol: after a $3 \mathrm{~min}$ rest in a sitting position, subjects climbed up and down $23 \mathrm{~cm}$ steps for 5 min at a rate of 30 steps per min controlled by a metronome which beat each second.

Subjects were verbally encouraged during the test. At the end of the test they rested for 5 min in a sitting position. Throughout the test session, heart rates (HR, expressed in beats per min, bpm) were recorded every $15 \mathrm{~s}$ with a Sport Tester (Polar Electro KY, Kempele, Finland). This device is composed of an emitting electrode attached to the chest and a receiver attached to the wrist. Subjects practiced climbing movements for several minutes beforehand. Initially, we tried to use a cycle ergometer, but as subjects had no previous experience in bicycling, they were unable to pedal at a fixed rhythm.

Physical fitness was estimated from the quickness of recovery after exercise. Two indices were calculated: 
- Recovery 1: difference in heartbeat between the last min of exercise and the first min of recovery.

- Recovery 2: difference in heartbeat between the last min of exercise and the average number of heartbeats during recovery.

Differences in heartbeat between rest and exercise or rest and recovery were also calculated.

\subsection{Physical activity}

It was decided that subjects should wear the cardio-frequencemeter for $12 \mathrm{~h}$ per day. This was generally the case for women and adolescents, but in practice, 10-13 years-old children did not support the device for more than 7 or $8 \mathrm{~h}$ due to either electrode displacement during play, excessive dryness of the skin at certain periods, or discomfort due to heat. Data were recorded between 8:00 a.m. and 8:00 p.m. Data were downloaded and interfaced with a PC. To analyze activity, we did not use Polar Electro software or other fixed value cut-offs. Instead, we adapted the flex-HR method (Spurr et al. 1988). The flex-HR is the critical HR value recorded between resting and the lowest value during exercise. To determine the resting HR, several measurements were taken at rest in the Lambaye group (Benefice 1998). Children' HR were recorded in a supine position, then while sitting, standing or walking slowly, after at least 5 min of adaptation time. HR values were compared with those recorded during the resting time of the step test and were not found to differ. Thus, we decided to calculate flex-HR as the mid-value between the lowest HR value in a sitting position (generally during the second min) and the lowest HR value of the first min of exercise. This procedure is generally adopted in the literature (Leonard 2003).

Several indices of physical activity levels were calculated:

- $\quad$ Percent of time spent below the resting value of the exercise test;

- $\quad$ Percent of time spent between the resting value and the flex-HR;

- $\quad$ Percent of time spent between the flex-HR and the maximal HR of the exercise test;

- Percent of time spent above the maximal HR.

These indices could also be synthesized in percent of time spent under $(<\mathrm{flex}-\mathrm{HR})$ or over (>flex-HR) the flex-HR. 


\subsection{Maximal strength}

Each subject undertook a grip strength test by squeezing a dynamometer made up of a rubber bulb connected to a manometer (Martin, Tuttlingen, Germany). Subjects were given 3 tries using both hands and the highest reading was analyzed. Because there were only slight differences between right and left hand in the grip test, the best value of either the right or left was indifferently retained for analysis. Results are expressed in kilopascals $(\mathrm{kPa})$.

\subsection{Statistical analysis}

Results of anthropometry, cardiorespiratory fitness, strength measurements and physical activity recording were presented in a comparative manner for 2 separated groups: a) the 1013 years-old group (children from Lambaye and Podor); and b) the group of women including adolescent girls and adult women. Next, the strength of the association between physical activity indices (dependent variables) and anthropometry and fitness measurements (independent variables) was tested by a multiple regression procedure. Normality of distribution was checked for each variable (D'Agostino or Martinez-Iglewicz tests) and could be deduced. Student's t-test was used to compare means. Uni- or bivariate analyses were done using the SPSS-11 for Windows package (SPSS Inc., 1989-2001). Regression analyses were done using the NCSS 2001 software package (Hintze J, NCSS 2000; Statistical System for Windows). NCSS enables treatment of one categorical variable in the model. Normality distribution and autocorrelation of residuals were checked. The level of probability of the risk $\alpha$ was set at $5 \%$. 


\section{Results}

Results of "individual competences" in terms of anthropometric characteristics, comparing children from Podor and Lambaye, are presented in table 1. Since there were no differences in age and sex distribution, no further stratification was performed. There was no difference in anthropometric measurements between the two groups, apart from the triceps skinfold, which was higher in Lambaye, and the BMI which was also greater in Lambaye than in Podor. Children from Lambaye displayed higher grip strength than those from Podor: grip strength in Lambaye $=62.0 \pm 15.7 \mathrm{kPa}$ versus $42.2 \pm 10.5 \mathrm{kPa}$ in Podor $(\mathrm{t}=7.5, \mathrm{p}<0.0001)$

Table 2 presents heartbeat indices calculated during the step test. Children from Lambaye recovered faster, immediately after exercise, than children from Podor. The difference between rest and recovery was also greater in Lambaye than in Podor, while the reverse was true for differences between exercise and rest. The flex-HR, calculated as indicated above, did not differ between the two groups.

Physical activity patterns are displayed in table 3. Children from Lambaye appeared to spend significantly more time performing vigorous activities (and conversely, less time at resting activities) than did children from Podor. This was also expressed as more time spent over the flex-HR.

Adult women were notably heavier and taller than adolescent girls, with more fat as well as more arm muscle mass (table 4). Although the adolescent girls were more than 15 years old and were nearly at the end of puberty, the difference in stature compared to female adults remained high, i.e., over $7 \mathrm{~cm}$. Interestingly, the grip strength of women was no greater than that of adolescents: grip strength for adolescents $=79.6 \pm 18.9 \mathrm{kPa}$ versus $84.0 \pm 18.3 \mathrm{kPa}$ for adult women $(t=1.0, \mathrm{n} . \mathrm{s}$.). Adult women displayed a greater capacity for recovery after stepping than did girls (table 5), but their flex-HR was lower. Adult women were more active than adolescent girls (table 6). They spent more time doing light and moderate activities over their flex-HR value activities than did adolescents. 
To further explore the relationship between physical activity levels and variables in fitness and body composition, a model was built. To eliminate redundancies between variables, a selection procedure was first applied and only variables resulting in a significant increase in the percent of variance were retained. Hence, BMI, AMC and triceps skinfold, representing body composition and Recovery 1 and Recovery 2 as indices of cardiorespiratory fitness, were selected as independent variables. Grip strength was also added. Multiple regression was then run between these variables and the percent of time spent over the flex-HR ( $>$ flex-HR) as a dependent variable. This represented the best single index of the physical activity level. The NCSS 2001 package enabled us to introduce one categorical variable, the subject group: Podor or Lambaye for the 10-13 years-old group; adolescent girls or adult women for the women's group.

Table 7 displays the main results of multiple regressions. In the case of 10-13 years-old children (upper rows), no relationship could be evidenced between activity level ( $>$ flex-HR) and body composition or physical fitness. The variable "group" was the only significant predictor of activity, and was interpreted as consisting of children from Lambaye having higher activity levels than children from Podor. It should be mentioned that anthropometric indices like $\mathrm{H}$-age or $\mathrm{W}$-age were not retained during the variable selection procedure. The coefficient of determination of this model was slight $\left(R^{2}=0.15\right)$ but significant $(p<0.03)$. Residuals were normally distributed and were not autocorrelated (Durbin-Watson test $=2.0$, no probability for positive or negative serial correlation).

In contrast, for the women's group, the independent variables, apart from hand grip strength and triceps skinfold, appeared to be significant predictors of the physical activity level. The variable "group" could be interpreted as consisting of adolescent girls having lower activity than adult women. The BMI had a negative influence on activity; the reverse was true for AMC. The coefficient of determination was twofold higher than in children: $R^{2}=0.30$ $(\mathrm{p}<0.001)$. Residuals were normally distributed and were not autocorrelated (Durbin-Watson test $=1.94$; no probability of serial positive or negative correlation). There were no multicolinearity problems: no variable had a variance inflation factor greater than 10 . 


\section{Discussion}

\subsection{Indication of nutritional deficiency}

In the 10-13 years-old as well as in the adolescent group, subjects displayed reduced body dimensions. This was evident when examining $\mathrm{W}$-age and $\mathrm{H}$-age $\mathrm{z}$-scores of children (WHO 1995). BMI was also low in children and adolescents. Subcutaneous skinfolds, arm circumference and subsequently AMC were well under published reference values (Frisancho 1981). Values for adult women also indicated a delicate body build.

As a whole, children and adolescents presented a slight degree of malnutrition, either in terms of reduced body mass or growth stunting. Indeed, a high prevalence of stunting $(16.9 \%, \mathrm{CI}$ : $12.5 \sim 19.7 \%)$ and wasting (13.3\%, CI: 9.7 16.4\%) has been reported in children less than 10 years of age living in the Podor area (Benefice and Simondon 1993). Their BMIs were low and the difference reported between children from Lambaye and Podor, though significant, was quite small $(0.7 \mathrm{~kg} / \mathrm{m} 2)$. The reason for this could be a seasonal food shortage which was more pronounced in Podor than in Niakhar. These findings could be explained by insufficient dietary intake at a time where body requirements are high. In fact, previous studies of food consumption performed in those areas pointed out that, while the overall per capita energy intake was satisfactory in Podor $(10.3 \pm 2.0 \mathrm{MJ} / \mathrm{d}), 35 \%$ of the population did not meet their requirements (Benefice and Simondon 1993). The same trend was reported in Niakhar, where the mean energy intake was $11.2 \pm 3.3 \mathrm{MJ} / \mathrm{d}$ ( $113 \%$ of requirement adequacy), but where $41 \%$ of the adolescents surveyed fell below age and sex requirements (Benefice et al. 2001). There were also deficiencies in nutrients like calcium, phosphorus and zinc, which played an important role in childhood growth.

In contrast to children, adult women seemed to be less nutritionally deprived. Hence, a previous study indicated no anthropometric changes in non-pregnant women across seasons. However, pregnant women did not gain sufficient weight during the agricultural period (Benefice et al. 1996), which could be interpreted as an incapacity to face the increase in energy requirements. Adolescent girls had anthropometric values inferior to those of adult women. This could largely be explained by the fact that they had not fully achieved their 
growth at the time of study. It should be underlined that, in industrialized countries, growth ceases in girls at about 15 years of age (Rogol et al. 2000).

\subsection{Group differences in physical fitness and physical activity levels}

After the step test, children from Lambaye recovered more quickly than those from Podor. Since they also attained higher HR values during exercise, their cardiorespiratory fitness appeared to be better than that of children from Podor. They also developed more maximal strength. Finally, they were more active in terms of the indices of physical activity employed. HR monitoring is considered to more accurately reflect child fitness than the activity level, since children who were more fit had lower cardiac stroke volume and hence lower HR for a given activity (Eston et al. 1998). However, in the present study, there was no difference in flex-HR between the two groups, contrary to a study in Nepal where active village boys spent more time over the flex-HR but had a lower flex-HR than urban children (Panter-Brick et al. 1996b). During rest and at the beginning of exercise, Lambaye and Podor children displayed the same HR pattern, leading to a similar flex-HR. But children from Lambaye were able to make a greater effort during controlled exercise and spent more time at moderate and vigorous activity. It could be concluded that children from Lambaye not only had better cardiorespiratory fitness than those from Podor, but also that they used them more intensely in their daily activity. It should be pointed out that, with respect to an active day length of $12 \mathrm{~h}$, children from Lambaye spent about $2 \mathrm{~h}$ and $50 \mathrm{~min}$ at moderate activity and $33 \mathrm{~min}$ at vigorous activity, which is considerable in comparison with studies from industrialized countries (Gilliam et al. 1981) and slightly higher than in studies dealing with active rural boys from a traditional society (Panter-Brick et al. 1996b). Children from Podor spent $1 \mathrm{~h}$ and 30 min at moderate activities and less than 7 min performing vigorous activities. A previous analysis using a fixed threshold to determine activity levels indicated that children spent $75 \%$ of their time at HR of less than $125 \mathrm{bpm}$. They were thus considered to be rather inactive (Benefice 1992). In the present study, the use of a threshold calculated from flex-HR after an individual calibration test led to more precise conclusions.

How can differences between the two groups be explained? This is a difficult question, since basic living conditions were quite similar in the two communities. Surveys were carried out during the dry season before agricultural work had begun. An obvious explanation could be the difference in climate and temperature at the time of the surveys. While, in Lambaye, 
recordings were done in March when nights were cool and permitted peaceful sleep after a hot day, this was not the case in Podor where the study was performed at the end of the dry season in June. At that time of year, a hot dry wind, the Harmattan, blew from the Sahara desert for several days and severely hindered the normal activities of the population. It has been argued that in traditional societies, a hot climate may affect the activity pattern so as to prevent heat stress (Ulijaszek 2001). However, in the present study, high temperatures did not necessarily persist and could not fully explain why children from Podor displayed lower cardiorespiratory fitness.

In the women's group, adults recovered more quickly than girls one minute after exercise, but not thereafter. They also spent more time at moderate but not vigorous activities. In that situation, differences could well be accounted for by the lower flex-HR of adult women and their apparent better cardiorespiratory fitness. A decline in activity with age has been reported in another group of adolescent girls from Niakhar (Benefice et al. 2001). Activity levels of girls are also generally lower than those of boys (Gilliam et al. 1981). The sex and age differences in activity patterns are clear-cut but did not completely clarify differences found between adult women and adolescent girls. The two groups did not come from the same area, and it is possible that the work load was heavier for women from Podor than for adolescents from Niakhar. In fact, previous studies suggested that adult women spent more time performing light domestic tasks (about $45 \%$ of daytime activity) (Benefice et al. 1996) than adolescent girls (about 18\% of daytime activity) (Benefice et al. 2001). Adult women also had less time for personal and social activities, including school: $20 \%$ versus $60 \%$. However, adolescents apparently spent more time doing strenuous tasks such as pounding millet, carrying water or cutting wood (10\% versus $7 \%$ ) and walking. While the extrapolation of these findings to the present study is not warranted, such differences in task patterns could well explain why, in the present study, adult women did not spend more time at vigorous activity than adolescent girls. On one hand, the higher level of activity by adult women could be explained by better fitness which might erroneously simulate a difference (Rowlands et al. 1999). On the other hand, this might be the consequence of greater involvement in less strenuous but more time-consuming home tasks on the part of adult women. Adolescent girls were less constrained by these monotonous chores, although they were required to help their mothers for a limited time doing strenuous tasks. Hence, there might exist close cooperation between mothers and daughters which would be an efficient way to reduce the work load while allowing the girls a great deal of free time. 


\subsection{Relationship between physiological competences and activity levels}

It might be assumed that in 10-13 years-old children, activity levels are independent of their bodily dimensions and cardiorespiratory characteristics, while in the women's group differences could be partly accounted for by a stronger body build and better fitness. This is exactly what emerges from multiple regression analysis: the percent of time spent over the flex-HR was associated with anthropometric or fitness characteristics in the women's group but not in that of children.

In children, the relationship between physical fitness and activity levels is generally weak (Livingstone 1994). Relationships seem stronger for adolescents. However, a review of 37 studies on adolescents indicated no relationship between fitness and activity in 17 of them, and the average correlation coefficient was low (Morrow and Freedson 1994). This could be due to methodological imperfections in the measurement of activity. Rowlands and colleagues found that the strength of the association between fitness and activity was stronger when using a movement counter rather than an HR monitor (Rowlands et al. 1999). Physical activity has several dimensions, and HR basically captures only one stress exerted upon the cardiovascular system due to activities. However, in the cited study, the authors used a fixed threshold of HR to determine levels of activity (HR > $139 \mathrm{bpm}$ and HR > $159 \mathrm{bpm}$ ) (Rowlands et al. 1999). In contrast, flex-HR is a reflection of the individual fitness of a given child. While it does not appear to be sufficiently reliable for clinical work, flex-HR is able to discriminate between activity patterns in different populations (Panter-Brick et al. 1996a). For this reason, its use is of interest in studies in non-industrialized populations (Leonard 2003, Yamauchi et al. 2001). Another reason for the absence of an association between fitness and HR monitoring in children could be the transient and brief nature of their activities (Bailey et al. 1995). Vigorous activities in children generally occur in short bouts of time and cannot be accurately registered by the apparatus because of the delay in HR response to change (Eston et al. 1998).

In contrast, the physiological competences of women were significant predictors of the time spent doing moderate to vigorous activities. Their body composition in terms of muscle mass was positively associated with their activity level, while BMI had a negative effect. The triceps skinfold had no effect. It is plausible that the BMI, with a lower variance than the triceps skinfold, more accurately represented the overall fat mass of the body in the regression 
equation. Comparison with the activity pattern of other women from developed countries is subject to caution because of the distinct nature and context of the activities of African women. It should be stated that: 1) there is no way for these women to avoid daily domestic tasks; 2) these tasks need to be undertaken manually because of the absence of automation to alleviate their burden, even for strenuous tasks such as fetching and carrying water or pounding millet. At first sight, it might be viewed as favorable that these women were free of excessive fat mass and developed good cardiorespiratory fitness correlated with a high level of activity. However, such positive traits should be placed in the context of their stressful physical and nutritional environments. Our findings suggest that these women used all their physiological competences to subsist at a daily level. However, we might ask what happens when these competences are surpassed during a natural or climatic disaster. Were these women able to mobilize supplementary competences to face added difficulties? Our results suggest that they worked at their extreme limit and were unable to surpass it. In that sense, the physiological characteristics of adult African women are a key limiting factor in community subsistence. In contrast, even slightly malnourished children are less limited and are able, under certain circumstances, to push back their limits, as illustrated here by children from Lambaye.

In conclusion, the results presented here fit well with the hypothesis of differential use of physiological competences to perform physical activities in relation to age, body composition and working status within the household. 


\section{Acknowledgements}

This study was made possible by a financial support of the R024 Research Unit of IRD (Institut de Recherche pour le Développement, France). Many thanks are due to our colleague Denis Garnier and to our research assistant Tofene Ndiaye. We are grateful to Professor Salimata Wade who helped us with her advices throughout the study. Many thanks also to Omar Sall, Daouda Ndiaye and Modou Mbow. We are especially grateful to all children, adolescents and women who were involved in the studies.

\section{Bibliography}

BAILEY, R. C., OLSON, J., PEPPER, S. L., PORSZASZ, J., BARSTOW, T. J.and COOPER, D. M., 1995, The level and tempo of children's physical activities: an observational study. Medicine and Sciences in Sports and Exercise, 27, 1033-1041.

BENEFICE, E., 1992, Physical activity and anthropometric and functional characteristics of mildly malnourished Senegalese children. Annals of Tropical Paediatrics, 12, 55-66. BENEFICE, E., 1998, Physical fitness and body composition in relation to physical activity in prebuscent Senegalese children. American Journal of Human Biology, 10, 385-396. BENEFICE, E., GARNIER, D.and NDIAYE, G., 2001, High levels of habitual physical activity in west African adolescent girls and relationship to maturation, growth, and nutritional status: results from a 3-year prospective study. American Journal of Human Biology, 13, 808-820.

BENEFICE, E.and SIMONDON, K., 1993, Agricultural development and nutrition among rural populations: a case study of the middle valley in Senegal. Ecology of Food and Nutrition, 31, 45-66.

BENEFICE, E., SIMONDON, K. and MALINA, R., 1996, Physical activity patterns and anthropometric changes in Senegalese women observed over a complete seasonal cycle. American Journal of Human Biology, 8, 251-261.

BLEIBERG, F., BRUN, T. A., GOIHMAN, S.and LIPPMAN, D., 1981, Food intake and energy expenditure of male and female farmers from Upper-Volta. British Journal of Nutrition, 45, 505-515. 
BRADFIELD, R. B., 1971, A technique for determination of usual daily energy expenditure in the field. American Journal of Clinical Nutrition, 24, 1148-1154.

BRUN, T., BLEIBERG, F.and GOIHMAN, S., 1981, Energy expenditure of male farmers in dry and rainy seasons in Upper-Volta. British Journal of Nutrition, 45, 67-75.

DE ONIS, M., FRONGILLO, E. A. and BLOSSNER, M., 2000, Is malnutrition declining? An analysis of changes in levels of child malnutrition since 1980. Bulletin of the World Health Organization, 78, 1222-1233.

ESTON, R. G., ROWLANDS, A. V.and INGLEDEW, D. K., 1998, Validity of heart rate, pedometry, and accelerometry for predicting the energy cost of children's activities. Journal of Applied Physiology, 84, 362-371.

FRISANCHO, A., 1981, New norms of upper limb fat and muscle areas for assessment of nutritional status. American Journal of Clinical Nutrition, 34, 2540-2545.

GARDNER, J. M., GRANTHAM-MCGREGOR, S. M., CHANG, S. M.and POWELL, C. A., 1990, Dietary intake and observed activity of stunted and non-stunted children in Kingston, Jamaica. Part II: Observed activity. European Journal of Clinical Nutrition, 44, 585593.

GARNIER, D.and BENEFICE, E., 2001, Habitual physical activity of Senegalese adolescent girls under different working conditions, as assessed by a questionnaire and movement registration. Annals of Human Biology, 28, 79-97.

GIAMPIETRO, M. and PIMENTEL, D., 1992, Energy efficiency and nutrition in societies based on human labor. Ecology of Food and Nutrition, 28, 11-32.

GILLIAM, T. B., FREEDSON, P. S., GEENEN, D. L. and SHAHRARAY, B., 1981, Physical activity patterns determined by heart rate monitoring in 6-7 year-old children.

Medicine and Sciences in Sports and Exercise, 13, 65-67.

GURNEY, J.and JELLIFFE, D., 1973, Arm anthropometry in nutritional assessment:

Nomogram for rapid calculation of muscle circumference and cross-sectional muscle and fat areas. American Journal of Clinical Nutrition, 26, 912-915.

JAIN, A., 2004, Fighting obesity. Brish Medical Journal, 328, 1327-1328.

KOHL, H., FULTON, J.and CASPERSEN, C., 2000, Assessment of physical activity among children and adolescents: A review and Synthesis. Preventive Medicine, 31, S54-S76.

LEONARD, W. R., 2003, Measuring human energy expenditure: What have we learned from the flex-heart rate method? American Journal of Human Biology, 15, 479-489.

LIVINGSTONE, M. B., 1994, Energy expenditure and physical activity in relation to fitness in children. Proceedings of the Nutrition Society, 53, 207-221. 
LOHMAN, T. G., ROCHE, A.and MARTORELL, R., 1988, Anthropometric standardization reference manual. Human kinetics Books, Champaign, Illinois.

MEEKS-GARDNER, J., GRANTHAM-MCGREGOR, S. M., CHANG, S. M., HIMES, J.

H.and POWELL, C. A., 1995, Activity and behavioral development in stunted and nonstunted children and response to nutritional supplementation. Child Development, 66, 1785-1797.

MONTOYE, H., KEMPER, H., SARIS, W.and WASHBURN, R., 1996, Measuring physical activity and energy expenditure. Human Kinetics, Champaign.

MORROW, J.and FREEDSON, P., 1994, Relationship between habitual physical activity and aerobic fitness in adolescents. Pediatric Exercise Science, 6, 315-329.

PANTER-BRICK, C., TODD, A., BAKER, R. and WORTHMAN, C., 1996a, Comparative study of flex heart rate in three samples of Nepali boys. American Journal of Human Biology, 8, 653-660.

PANTER-BRICK, C., TODD, A., BAKER, R. and WORTHMAN, C., 1996b, Heart rate monitoring of physical activity among village, school, and homeless Nepali boys. American Journal of Human Biology, 8, 661-672.

ROGOL, A. D., A., C. P.and ROEMMICH, J. N., 2000, Growth and pubertal development in children and adolescents: effects of diet and physical activity. American Journal of Clinical Nutrition, 72, 521S-528S.

ROWLANDS, A. V., ESTON, R. G.and INGLEDEW, D. K., 1999, Relationship between activity levels, aerobic fitness, and body fat in 8- to 10-yr-old children. Journal of Applied Physiology, 86, 1428-1435.

ROWLANDS, A. V., INGLEDEW, D. K.and ESTON, R. G., 2000, The effect of type of physical activity measure on the relationship between body fatness and habitual physical activity in children: a meta-analysis. Annals of Human Biology, 27, 479-497.

SARIS, W. H., 1986, Habitual physical activity in children: methodology and findings in health and disease. Medicine and Sciences in Sports and Exercise, 18, 253-263.

SPURR, G. B., 1990, Physical activity and energy expenditure in undernutrition. Progress in Food and Nutrition Sciences, 14, 139-192.

SPURR, G. B., BARAC-NIETO, M.and MAKSUD, M. G., 1975, Energy expenditure cutting supercane. Journal of Applied Physiology, 39, 990-996.

SPURR, G. B., BARAC-NIETO, M.and MAKSUD, M. G., 1977, Productivity and maximal oxygen consumption in sugar cane cutters. American Journal of Clinical Nutrition, 30, 316321. 
SPURR, G. B., PRENTICE, A. M., MURGATROYD, P. R., GOLDBERG, G. R., REINA, J. C.and CHRISTMAN, N. T., 1988, Energy expenditure from minute-by-minute heart-rate recording: comparison with indirect calorimetry. American Journal of Clinical Nutrition, 48, 552-559.

SPURR, G. B.and REINA, J. C., 1988, Influence of dietary intervention on artificially increased activity in marginally undernourished Colombian boys. European Journal of Clinical Nutrition, 42, 835-846.

THOMAS, D.and FRANKENBERG, E., 2002, Health, nutrition and prosperity: a microeconomic perspective. Bulletin of the World Health Organization, 80, 106-113. TORUN, B.and VITERI, F. E., 1993, Nutrition and function, with emphasis on physical activity. International Child Health, 4, 15-26.

ULIJASZEK, S. J., 2001, Work and climate in traditional subsistence economies. Journal of Physiological Anthropology and Applied Human Science, 20, 105-110.

WHO, 1995, Physical status: The use and interpretation of anthropometry. Report of a WHO expert committee. World Health Organization, Geneva.

YAMAUCHI, T., UMEZAKI, M.and OHTSUKA, R., 2000, Energy expenditure, physical exertion and time allocation among Huli-speaking people in the Papua New Guinea Highlands. Annals of Human Biology, 27, 571-585.

YAMAUCHI, T., UMEZAKI, M.and OHTSUKA, R., 2001, Influence of urbanisation on physical activity and dietary changes in Huli-speaking population: a comparative study of village dwellers and migrants in urban settlements. British Journal of Nutrition, 85, 65-73. 
Table 1 Comparison of anthropometric dimensions between 10-13 years-old children

\begin{tabular}{|c|c|c|c|c|c|c|}
\hline Measurements $^{1}$ & Groups & $\mathrm{N}$ & Mean & $\mathrm{SD}^{2}$ & $\mathrm{t}$ & $\mathrm{p}^{3}$ \\
\hline \multirow[t]{2}{*}{ Age (years) } & Lambaye & 40 & 10.9 & 0.9 & \multirow[t]{2}{*}{0.9} & \multirow[t]{2}{*}{ n.s } \\
\hline & Podor & 59 & 11.2 & 1.8 & & \\
\hline \multirow[t]{2}{*}{ Height $(\mathrm{cm})$} & Lambaye & 40 & 138.2 & 8.1 & \multirow[t]{2}{*}{1.0} & \multirow[t]{2}{*}{ n.s } \\
\hline & Podor & 59 & 139.9 & 8.8 & & \\
\hline \multirow[t]{2}{*}{ Weight (kg) } & Lambaye & 40 & 29.7 & 5.5 & \multirow[t]{2}{*}{0.5} & \multirow[t]{2}{*}{ n.s } \\
\hline & Podor & 59 & 29.2 & 5.2 & & \\
\hline \multirow[t]{2}{*}{ Arm circumference $(\mathrm{cm})$} & Lambaye & 40 & 17.7 & 1.6 & \multirow[t]{2}{*}{0.4} & \multirow[t]{2}{*}{ n.s } \\
\hline & Podor & 59 & 17.6 & 1.6 & & \\
\hline \multirow[t]{2}{*}{ Tric } & Lambaye & 40 & 6.6 & 2.5 & \multirow[t]{2}{*}{2.0} & \multirow[t]{2}{*}{0.05} \\
\hline & Podor & 59 & 5.8 & 1.6 & & \\
\hline \multirow[t]{2}{*}{$\mathrm{Bic}$} & Lambaye & 40 & 4.8 & 1.5 & \multirow[t]{2}{*}{0.1} & \multirow[t]{2}{*}{ n.s } \\
\hline & Podor & 59 & 4.7 & 1.4 & & \\
\hline \multirow[t]{2}{*}{ Sub-scap } & Lambaye & 40 & 5.3 & 1.4 & \multirow[t]{2}{*}{0.2} & \multirow[t]{2}{*}{ n.s } \\
\hline & Podor & 59 & 5.3 & 1.3 & & \\
\hline \multirow[t]{2}{*}{ Sup-il } & Lambaye & 40 & 5.2 & 2.0 & \multirow[t]{2}{*}{0.4} & \multirow[t]{2}{*}{ n.s } \\
\hline & Podor & 59 & 5.3 & 1.5 & & \\
\hline \multirow[t]{2}{*}{$\mathrm{AMC}(\mathrm{cm})$} & Lambaye & 40 & 15.6 & 1.3 & \multirow[t]{2}{*}{0.5} & \multirow[t]{2}{*}{ n.s. } \\
\hline & Podor & 59 & 15.7 & 1.4 & & \\
\hline \multirow[t]{2}{*}{ H-age (z-score) } & Lambaye & 40 & -0.8 & 1.0 & \multirow[t]{2}{*}{0.1} & \multirow[t]{2}{*}{ n.s } \\
\hline & Podor & 59 & -0.8 & 1.1 & & \\
\hline \multirow[t]{2}{*}{ W-age (z-score) } & Lambaye & 40 & -1.1 & 0.8 & \multirow[t]{2}{*}{1.7} & \multirow[t]{2}{*}{0.08} \\
\hline & Podor & 59 & -1.4 & 0.8 & & \\
\hline BMI $\left(\mathrm{kg} / \mathrm{m}^{2}\right)$ & Lambaye & 40 & 15.5 & 1.9 & 2.2 & 0.03 \\
\hline & Podor & 59 & 14.8 & 1.3 & & \\
\hline
\end{tabular}

${ }^{1}$ Measurement abbreviations: Tric $=$ triceps skinfold; Bic= bíceps skinfold; Sub-scap $=$ subscapular skinfold; Sup-il = supra-iliac skinfold;

${ }^{2} \mathrm{SD}=$ standard deviation

${ }^{3} \mathrm{p}=$ probability; n.s. $=$ not significant 
Table 2 Comparison of heartbeat indices during a step-test between 10-13 years-old children

\begin{tabular}{|c|c|c|c|c|c|c|}
\hline HR indices & Groups & $\mathrm{N}$ & Mean & SD & $\mathrm{t}$ & $\mathrm{p}$ \\
\hline \multirow[t]{2}{*}{ Recovery 1 (bpm $\left.{ }^{1}\right)$} & Lambaye & 40 & 37.6 & 13.9 & 3.3 & 0.001 \\
\hline & Podor & 59 & 47.2 & 14.1 & & \\
\hline \multirow[t]{2}{*}{ Recovery 2 (bpm) } & Lambaye & 40 & 52.8 & 15.4 & 1.2 & n.s. \\
\hline & Podor & 59 & 56.3 & 12.5 & & \\
\hline \multirow[t]{2}{*}{ Flex-HR (bpm) } & Lambaye & 40 & 115.3 & 11.6 & 0.7 & n.s. \\
\hline & Podor & 59 & 117.0 & 12.7 & & \\
\hline \multirow[t]{2}{*}{ Rest-Recovery $^{2}$ (bpm) } & Lambaye & 40 & -12.4 & 7.9 & 4.8 & 0.0001 \\
\hline & Podor & 59 & -4.9 & 7.3 & & \\
\hline \multirow[t]{2}{*}{ Exercise-rest $^{3}(\mathrm{bpm})$} & Lambaye & 40 & 68.0 & 13.4 & 6.1 & 0.0001 \\
\hline & Podor & 59 & 52.3 & 11.6 & & \\
\hline
\end{tabular}

${ }^{1} \mathrm{bpm}$ : beats per minute

${ }^{2}$ Rest - recovery: average HR value during rest minus average HR value during recovery

${ }^{3}$ Exercise- rest: HR at the end of exercise ( 5 min) minus HR at 2 minutes of rest 
Table 3 Comparison of physical activity indices between 10-13 years-old children

\begin{tabular}{llllllr}
\hline Physical activity indices $^{1}$ & Groups & N & Mean & SD & t & P \\
& Lambaye & 40 & 30.3 & 30.4 & 3.9 & 0.001 \\
& Podor & 56 & 53.3 & 26.9 & & \\
\% rest & Lambht & & & & & \\
& Podor & 56 & 32.7 & 18.4 & & \\
\% moderate & Lambaye & 40 & 23.5 & 18.8 & 3.2 & 0.001 \\
& Podor & 56 & 12.9 & 13.0 & & \\
\% vigorous & Lambaye & 40 & 4.6 & 4.7 & 5.3 & 0.001 \\
& Podor & 56 & 0.9 & 1.5 & & \\
$<$ flex-HR & Lambaye & 40 & 71.8 & 21.9 & 3.9 & 0.001 \\
& Podor & 56 & 86.0 & 13.6 & & \\
$>$ flex-HR & Lambaye & 40 & 28.2 & 21.9 & 3.9 & 0.001 \\
& Podor & 56 & 13.9 & 13.6 & & \\
\hline
\end{tabular}

${ }^{1}$ Physical activity indices abbreviations:

- $\quad \%$ rest : $\%$ of heartbeats $<$ HR value at rest;

- $\quad \%$ light : \% of heartbeats between HR value at rest and the flex-HR ;

- $\quad \%$ moderate : \% of heartbeats between the flex-HR and HR value at the end of exercise, $\%$ vigorous : $\%$ of heartbeats $>\mathrm{HR}$ at the end of exercise

- $\quad<$ flex-HR $=\%$ heartbeats $<$ flex-HR;

- $\quad>$ flex-HR $=\%$ heartbeats $>$ flex-HR; 
Table 4 Comparison of anthropometric dimensions between adolescents and women

\begin{tabular}{llrrrrc}
\hline Measurements $^{1}$ & Groups & $\mathrm{N}$ & Mean & $\mathrm{SD}$ & $\mathrm{t}$ & $\mathrm{p}$ \\
\hline Age (years) & Adolescents & 43 & 15.4 & 0.5 & 12.2 & 0.001 \\
& Women & 30 & 27.0 & 6.2 & & \\
Height $(\mathrm{cm})$ & Adolescents & 43 & 156.9 & 7.7 & 4.4 & 0.001 \\
& Women & 30 & 163.8 & 4.3 & & \\
Weight $(\mathrm{kg})$ & Adolescents & 43 & 43.2 & 7.0 & 8.8 & 0.001 \\
& Women & 30 & 61.2 & 10.3 & & \\
Arm circumference $(\mathrm{cm})$ & Adolescents & 43 & 22.1 & 2.1 & 6.8 & 0.001 \\
& Women & 30 & 26.5 & 3.4 & & \\
Tric & Adolescents & 43 & 9.7 & 3.5 & 4.14 & 0.001 \\
& Women & 30 & 14.6 & 6.5 & & \\
AMC (cm) & Adolescents & 43 & 19.0 & 1.4 & 7.9 & 0.001 \\
& Women & 30 & 21.9 & 1.6 & & \\
BMI & Adolescents & 43 & 17.6 & 2.2 & 7.9 & 0.001 \\
& Women & 30 & 22.7 & 3.3 & & \\
\hline
\end{tabular}

${ }^{1}$ Measurement abbreviations: Tric: triceps skinfold; AMC: arm muscle circumference 
Table 5 Comparison of heartbeat indices during a step-test between adolescents and women

\begin{tabular}{|c|c|c|c|c|c|c|}
\hline HR indices & Groups & $\mathrm{N}$ & Mean & SD & $\mathrm{t}$ & $\mathrm{p}$ \\
\hline \multirow{2}{*}{ Recovery $1(\mathrm{bpm})^{1}$} & Adolescents & 41 & 34.1 & 17.7 & \multirow[t]{2}{*}{2.4} & \multirow[t]{2}{*}{0.01} \\
\hline & Women & 30 & 43.7 & 14.4 & & \\
\hline \multirow[t]{2}{*}{ Recovery 2 (bpm) } & Adolescents & 41 & 52.4 & 10.1 & \multirow[t]{2}{*}{1.3} & \multirow[t]{2}{*}{ n.s. } \\
\hline & Women & 30 & 55.9 & 12.0 & & \\
\hline \multirow[t]{2}{*}{ Flex-HR (bpm) } & Adolescents & 41 & 118.7 & 12.6 & \multirow[t]{2}{*}{5.1} & \multirow[t]{2}{*}{0.0001} \\
\hline & Women & 30 & 104.2 & 10.7 & & \\
\hline \multirow[t]{2}{*}{ Rest-Recovery (bpm) ${ }^{2}$} & Adolescents & 41 & -10.4 & 10.6 & \multirow[t]{2}{*}{1.7} & \multirow[t]{2}{*}{0.09} \\
\hline & Women & 30 & -14.6 & 9.6 & & \\
\hline \multirow[t]{2}{*}{ Exercise-rest $(\mathrm{bpm})^{3}$} & Adolescents & 41 & 66.1 & 15.6 & \multirow[t]{2}{*}{1.4} & \multirow{2}{*}{ n.s. } \\
\hline & Women & 30 & 71.6 & 16.9 & & \\
\hline
\end{tabular}

\footnotetext{
${ }^{1}$ bpm: beats per minute

${ }^{2}$ Rest - recovery: average HR value during rest minus average HR value during recovery

${ }^{3}$ Exercise- rest: HR at the end of exercise ( 5 min) minus HR at 2 minutes of rest
} 
Table 6 Comparison of physical activity indices between adolescent girls and women

\begin{tabular}{lllllll}
\hline Physical activity indices $^{1}$ & Groups & $\mathrm{N}$ & Mean & $\mathrm{SD}$ & $\mathrm{t}$ & $\mathrm{p}$ \\
& & & & & & \\
\hline \% rest & Adolescents & 43 & 48.9 & 25.4 & 4.29 & 0.00 \\
& Women & 30 & 24.2 & 22.2 & & \\
\% light & Adolescents & 43 & 36.7 & 17.9 & -3.94 & 0.00 \\
& Women & 30 & 53.2 & 17.2 & & \\
\% moderate & Adolescents & 43 & 13.1 & 14.1 & -2.10 & 0.04 \\
& Women & 30 & 21.5 & 20.2 & & \\
\% vigorous & Adolescents & 43 & 1.4 & 1.3 & 1.15 & 0.25 \\
& Women & 30 & 1.0 & 1.0 & & \\
$<$ flex-HR & Adolescents & 43 & 85.5 & 14.4 & 1.98 & 0.05 \\
$>$ flex-HR & Women & 30 & 77.4 & 20.5 & & \\
& Adolescents & 43 & 14.5 & 14.4 & -1.98 & 0.05 \\
& Women & 30 & 22.6 & 20.5 & & \\
& & & & & &
\end{tabular}

${ }^{1}$ Physical activity indices abbreviations:

- $\%$ rest : $\%$ of heartbeats $<$ HR value at rest;

- $\%$ light : $\%$ of heartbeats between HR value at rest and the flex-HR ;

- $\%$ moderate : \% of heartbeats between the flex-HR and HR value at the end of exercise, \% vigorous : \% of heartbeats $>\mathrm{HR}$ at the end of exercise

- $\quad<$ flex-HR $=\%$ heartbeats $<$ flex-HR;

- $\quad>$ flex-HR $=\%$ heartbeats $>$ flex-HR; 
Table 7 Summary of a multiple regression analysis between percent of time spent above the Flex-HR ( $>\mathrm{fHR})$ as dependent variable and AMC, BMI, maximal grip strength, triceps skinfold, and recovery indices as independent variables.

a) 10-13 years-old children

\begin{tabular}{|c|c|c|c|c|c|}
\hline $\begin{array}{l}\text { Independent } \\
\text { variable }^{1}\end{array}$ & $\begin{array}{l}\text { Regression } \\
\text { coefficient }\end{array}$ & Standard error & $\mathrm{R}^{2}$ & $\mathrm{t}$ test & $\mathrm{p}^{2}$ \\
\hline $\mathrm{AMC}$ & -0.03 & 2.25 & 0.002 & -0.014 & n.s. \\
\hline $\mathrm{BMI}$ & -1.05 & 1.95 & 0.010 & -0.54 & n.s. \\
\hline Grip strength & 0.03 & 0.17 & 0.053 & 0.21 & n.s. \\
\hline (Group) & 11.76 & 5.82 & 0.075 & 2.02 & 0.04 \\
\hline Tric & 0.66 & 1.02 & 0.003 & 0.65 & n.s. \\
\hline Recovery 1 & -0.23 & 0.26 & 0.010 & -0.87 & n.s. \\
\hline Recovery 2 & 0.10 & 0.28 & 0.0015 & 0.39 & n.s. \\
\hline $\mathrm{R}^{2}$ (model) & 0.15 & & & & \\
\hline F ratio & 2.34 & $\mathrm{p}<0.03$ & & & \\
\hline
\end{tabular}

b) Adolescent girls and women

\begin{tabular}{|c|c|c|c|c|c|}
\hline $\begin{array}{l}\text { Independent } \\
\text { variable }\end{array}$ & $\begin{array}{l}\text { Regression } \\
\text { coefficient }\end{array}$ & Standard error & $\mathrm{R}^{2}$ & $\mathrm{t}$ test & $\mathrm{p}$ \\
\hline $\mathrm{AMC}$ & 5.49 & 2.14 & 0.002 & 2.55 & 0.01 . \\
\hline BMI & -4.17 & 1.52 & 0.010 & 2.73 & 0.008 \\
\hline Grip strength & -0.05 & 0.11 & 0.053 & 0.51 & n.s. \\
\hline (Group) & -14.25 & 5.77 & 0.075 & 2.46 & 0.01 \\
\hline Tric & 0.16 & 0.60 & 0.003 & 0.27 & n.s. \\
\hline Recovery 1 & -0.49 & 0.15 & 0.010 & 3.10 & 0.002 \\
\hline Recovery 2 & 0.87 & 0.24 & 0.0015 & 3.61 & 0.0006 \\
\hline $\mathrm{R}^{2}$ (model) & 0.30 & & & & \\
\hline F ratio & 4.00 & $\mathrm{p}<0.001$ & & & \\
\hline
\end{tabular}

${ }^{1}$ Independent variables: $\mathrm{AMC}=$ arm muscle circumference; $\mathrm{BMI}=$ body mass index; Group $=$ group of children (from Lambaye or Podor) or adolescent girls and women; Tric $=$ triceps skinfold; Recovery 1: difference between last minute of exercise and $1^{\text {st }}$ minute of recovery; recovery 2: difference between last minute of exercise and mean HR during recovery.

${ }^{2} \mathrm{t}$ test and $\mathrm{p}$ value to test the significance of the coefficient of regression 